\title{
恣㞾芯 Pensar el pensamiento con el que pensamos: alcances y límites del feminismo teórico
}

\author{
Olga Vásquez Monzón \\ Investigadora independiente
}

Resumen: Este texto forma parte de una constatación: ni los aportes conceptuales posicionados por la teoría feminista ni el activismo político desplegado a lo largo de casi 200 años han logrado desmontar el imaginario colectivo que explica las diferencias individuales - no sólo de género sino también de etnia, edad e incluso estatus económico- a partir de un esquema jerárquico. Desde la perspectiva de los estudios culturales, este texto propone una revisión de estos marcos de interpretación y explora algunas pistas que permitirían pensar modelos de convivencia incluyentes y democráticos.

Palabras clave: Mujeres, feminismo, teoría feminista, filosofía, pensamiento occidental, estudios culturales.

Abstract: This text is based on a finding: neither the conceptual contributions positioned by feminist theory nor the political activism deployed over almost two hundred years have managed to dismantle the collective imagination that explains individual differences - not only of gender but also of ethnicity, age and even economic status - from a hierarchical scheme. From the perspective of cultural studies, this text proposes a revision of these frameworks of interpretation and explores some clues that would allow generating models of inclusive and democratic coexistence.

Key words: Women, Feminism, Feminist Theory, Philosophy, Western Thought, Cultural Studies. 


\section{Introducción}

El potencial crítico de los diversos feminismos teóricos surgidos a lo largo de los siglos XIX y XX es innegable. Su andamiaje conceptual ha contribuido a complejizar el análisis del modelo económico, social, político y cultural hegemónico construido sobre la base excluyente del sistema sexo-género. Sin embargo, ni los aportes conceptuales posicionados por la teoría feminista ni el activismo político desplegado a lo largo de casi 200 años han logrado desmontar el imaginario colectivo que explica las diferencias individuales - no sólo de género sino también de etnia, edad e incluso estatus económico- a partir de un esquema jerárquico.

Ya en la última década del siglo pasado, Riane Eisler constató que, aunque el movimiento de las mujeres del siglo $X X-y$ con éste la expansión global de la conciencia feminista- no tenía precedentes en cuanto a profundidad y fuerza, había sido en gran parte reactivo al adoptar la forma de reafirmación intelectual y protesta social (Eisler, 1992, p. 67). Veinte años más tarde, un grupo de investigadores del Consejo Latinoamericano de Ciencias Sociales $^{1}$ señaló que, si bien el pensamiento feminista había producido una sólida teoría crítica para demostrar los múltiples rostros de la dominación, la cultura patriarcal seguía instalada en la subjetividad (Carosio, 2012, p. 14). Ambas afir- maciones detectan la misma deuda en la vertiente teórico feminista: el discurso -aun cuando muestra articulación y rigurosidad- no alcanzó impactar hasta el nivel de la subjetividad para transformarla.

Este límite en el alcance de la teoría feminista permitiría entender que, pese a la abundante producción de discursos críticos en torno al sistema sexo-género, en pleno siglo XXI las relaciones de convivencia cotidiana continúan cobijadas bajo el marco de interpretación que jerarquiza las diferencias. Como señaló Alicia Puleo, "la fortaleza de costumbres y de los prejuicios arraigados en la sociedad, y por ende, en los ilustrados en tanto que pertenecen a ésta" (Puleo, 1993, p. 14) puso en evidencia que el auge del racionalismo ilustrado resultó insuficiente para transformar costumbres y erradicar prejuicios milenarios. Por el contrario, como señaló Castoriadis: la constitución de un nuevo imaginario, centrado sobre lo "pseudo-racional" afectó a los elementos últimos del mundo y a su organización total (Castoriadis, 1983, p. 226). En el siglo XIX, esta pseudo-racionalidad produjo nuevos argumentos filosóficos, científicos y religiosos que fundamentaron la constitución de las relaciones de convivencia y el diseño de instituciones que no sólo mantuvieron sino que reforzaron el modelo de dominación jerárquica. 
Desde la perspectiva de los estudios culturales, ${ }^{2}$ este texto propone una revisión de este proceso. Inicia con un recorrido genealógico que muestra la permanencia de ideas, representaciones e imágenes milenarias sobre la inferioridad de las mujeres en los discursos filosóficos, científicos y religiosos más difundidos en Occidente. En un segundo momento, hace un breve recorrido histórico del pensamiento feminista y sus intentos por desmontar estas ideas en el terreno del logos, tanto en Occidente como en El Salvador. Para finalizar, propone pistas que permitan revitalizar la theoria ${ }^{3}$ feminista a partir de la incorporación de la vertiente mítica del pensamiento bajo el supuesto de que es necesario comprometer los afectos, la imaginación y la creatividad para desmontar los viejos prejuicios, generar narrativas, representaciones, imágenes y modelos de relaciones cotidianas e instituciones alternativas al modelo hegemónico.

\section{Orígenes}

La concepción occidental sobre la naturaleza de las mujeres $-y$ en consecuencia su función socialencuentra su origen en las antiguas narrativas griegas. Amparo Gómez Rodríguez (2004) muestra que el orden de lo masculino y lo femenino quedó instaurado en la obra de Hesíodo con el mito de Prometeo. Tras el robo del fuego, Zeus castigó a los hombres enviándoles un mal que les alegrara el corazón: modeló la primera mujer -semejante en rostro a las diosas inmortales- que introdujo todos los males que azotan al hombre, pues "de ella desciende la funesta estirpe (genos femenino) y las tribus de las mujeres, gran calamidad para los hombres que con ellas viven" (Gómez Rodríguez, 2004, p. 37).

Esta antigua narrativa aportó tres nociones que han sido fundamento de las representaciones femeninas construidas en Occidente: la mujer como desgracia y castigo, pues rompe la armonía del perfecto mundo masculino; la mujer como criatura de categoría inferior, ya que fue hecha y no engendrada por los dioses; y la mujer como naturaleza primitiva, depositaria de deseos pasionales y carente de raciocinio. Sobre esta base, la cultura occidental identificó lo masculino con lo bueno, lo racional y, por tanto, lo superior; y lo femenino con lo malo, lo emocional y, por tanto, lo inferior. A partir de esta división, señala Hellen Buss Mitchell, "era fácil declarar que así como la razón debe gobernar las emociones y los deseos del cuerpo, el hombre debe gobernar a la mujer en la sociedad" (Buss Mitchell, 1998, p. 124).

Aunque la filosofía griega clásica se concibió a sí misma como supe- 
ración de las antiguas narrativas, el riguroso ejercicio lógico conceptual de los primeros filósofos no sólo no cuestionó las anteriores premisas sobre las diferencias entre los géneros sino que añadió otros elementos que reforzaron el argumento de la natural inferioridad femenina. Además de ratificar la concepción de la inferioridad natural de las hembras, los amantes de la sabiduría ratificaron también su incapacidad política, ética y legal para la ciudadanía, para la administración de sus propios bienes y para el aprendizaje (Gómez Rodríguez, 2004).

En el primer siglo de la era actual, el cristianismo primitivo ${ }^{4}$ generó una pequeña ruptura en esta concepción de jerarquía sexual que imperaba en la cultura occidental de aquel momento. El teólogo suizo Hans Küng (2002) explica que en las primeras comunidades cristianas se vivió un fenómeno de relativización de los antiguos roles sexuales, ya que las mujeres que participaron en este movimiento tenían reconocimiento y funciones iguales a las de los varones. Sin embargo, estos cambios fueron interpretados por muchos "como un ataque al papel masculino y las funciones añejas de dirección. Como caso excepcional podría tolerarse, pero como fenómeno de masas la Iglesia lo consideró cada vez más una amenaza" (Küng, 2002, p. 39). Como consecuencia, el cristianismo imperial adoptó la mentalidad jerár- quica por encima de las dinámicas de igualdad de las primeras iglesias.

A la mentalidad jerárquica de la naciente institución eclesial se sumaron los planteamientos de Agustín de Hipona, en el siglo IV. El obispo reforzó la idea de la inferioridad femenina cuando culpó a la mujer de la unión carnal y la hizo responsable de la transmisión del pecado original a su descendencia. Durante los siguientes diez siglos, este pensamiento imperó en la construcción de imágenes y representaciones que reforzaron los elementos ya presentes en la mitología griega clásica con respecto a la mujer: fuerza incontrolable, cuerpo seductor, naturaleza irracional. ${ }^{5}$ No es extraño que, entre los siglos $X V$ y $\mathrm{XVII}$, los discursos y las representaciones religiosas, científicas y filosóficas de la mujer reflejaran la necesidad de contenerla y de hacer de su presencia una suerte de ausencia (Zemon Davis y Farge, 2000).

En el siglo XVIII, el movimiento cultural e intelectual de la Ilustración situó una nueva concepción del conocimiento que exigía la transformación del orden político y social. Pese a que este momento de ruptura epistemológica era propicio para cuestionar el paradigma de la inferioridad natural de las mujeres, la filosofía, la ciencia y la religión aportaron nuevos argumentos para reforzar la antigua concepción. 
Tres filósofos resultan representativos del pensamiento sobre la inferioridad natural de las mujeres: Juan J. Rousseau, Arthur Schopenhauer y Augusto Comte. Aunque sus voces no son las únicas del pensamiento ilustrado, sus planteamientos parecen recoger el sentido común de la época ante los atisbos de los primeros movimientos intelectuales femeninos. ${ }^{6}$ Así, las ideas expresadas por estos tres filósofos determinaron, en buena medida, la reestructuración de las relaciones del nuevo orden social y político sobre las bases del antiguo patriarcado.

En su obra Emilio, publicada en 1762, Rousseau ofrece una clara caracterización de la condición femenina a partir de dos elementos fundamentales: la maternidad como destino y la sujeción al marido como estado social (Cobo, 1995). Según el filósofo, había en las mujeres un sentido interno que las guiaba a cumplir con los deberes que se desprendían de su naturaleza biológica. Enmarcada en las coordenadas del espacio doméstico, su realización consistía en merecer la estimación del esposo, por lo que su educación debía estar circunscrita a los oficios prácticos propios de su sexo. Rosa Cobo acierta cuando sostiene que la razón rousseauniana no sólo no impugnó la razón patriarcal sino que la reforzó ideológicamente: su concepto de estado de naturaleza ocultó la sujeción de las mujeres al mostrarla como hecho natural.

Augusto Comte tampoco cuestionó el sentido común alimentado durante milenios. En su obra Sistema de política positiva o tratado de sociología que instituye la religión de la humanidad, el llamado fundador del positivismo consideró que las mujeres estaban mejor dispuestas para subordinar la inteligencia al sentimiento. Esta natural tendencia derivó en la asignación de un rol doméstico:

\begin{abstract}
[...] mejor dispuestas siempre a subordinar al sentimiento, la inteligencia y la actividad, las mujeres constituyen espontáneamente los seres intermedios entre la humanidad y los hombres. El gran ser les confía especialmente su providencia moral para sostener el cultivo directo y continuo de la afección universal en medio de las tendencias teóricas y prácticas, que nos desvían sin cesar [...] la importancia y la dificultad de tal oficio exigen que cada uno de nosotros esté siempre situado bajo la providencia particular de uno de estos ángeles que de él responden al Gran Ser. Este guardián moral comporta tres tipos naturales, la madre, la esposa y la hija. (Comte, 1998, p. 102).
\end{abstract}




\begin{abstract}
Una idea similar se evidencia en alemán Arthur Schopenhauer, publiel ensayo "Las mujeres", del filósofo cado en 1851:
\end{abstract}

Solo el aspecto de la mujer revela que no está destinada ni a los grandes trabajos de la inteligencia ni a los grandes trabajos materiales. Paga su deuda a la vida, no con la acción, sino con el sufrimiento, los dolores de parto, los inquietos cuidados de la infancia; tiene que obedecer al hombre, ser una compañera pacienzuda que le serene. Las mujeres, al ser faltas de inteligencia, solo pueden ser aptas para cuidarnos y educarnos en la primera infancia, es que ellas mismas continúan siendo pueriles, fútiles y limitadas de inteligencia. Permanecen toda su vida niños grandes, una especie de intermedio entre el niño y el hombre. (Schopenhauer, 1998, p. 57).

Aunque reconoce la existencia le permite fijarse sino en las cosas de la razón femenina, Schopenhauer próximas de su limitado horizonte: señala que su raciocinio débil no

La débil razón de la mujer no participa de esas ventajas ni de esos inconvenientes. Padece miopía intelectual que, por una especie de intuición, le permite ver de un modo penetrante las cosas próximas; pero su horizonte es muy pequeño y se le escapan las cosas lejanas. De ahí viene el que todo cuando no es inmediato, o sea lo pasado y lo venidero, obre más débilmente sobre la mujer que sobre nosotros. (Schopenhauer, 1998, p. 59).

Por esta natural inferioridad, las mujeres debían permanecer en el ámbito de lo doméstico cuyas tareas no le exigían más de lo que podía dar. La música, el dibujo, el baile, las labores de jardín y algunas de campo eran suficientes entretenimientos para su limitada capacidad.

En el campo de las ciencias naturales, el reduccionismo biológico que sesgó la investigación científica del siglo XIX también afianzó la concep- ción de inferioridad natural de las mujeres. Pese a que las revoluciones republicanas enarbolaron la bandera de la igualdad y se beneficiaron de la participación de mujeres organizadas (Godineau en Duby y Perrot, 1993), ${ }^{7}$ la capacidad intelectual de las mujeres siguió cuestionada y, con ella, su legítimo derecho a participar en igualdad de condiciones en el nuevo orden social. 
Una nueva concepción de los sexos afirmó la diferencia anatómica radical y la divergencia biológica pasó a ser la clave de la inferioridad femenina: después del mito de la mujer imperfecta se instauró el mito de la mujer útero (Gómez Rodríguez, 2004, p. 56). Esta concepción fue alimentada por varios estudios de cuño evolutivo que afirmaron que las facultades mentales superiores observación, razón, invención, imaginación- las habían desarrollado los hombres al tener que defender a sus hembras y competir por ellas. Por el contrario, las labores de crianza no requerían de las hembras más que cualidades pasivas y domésticas.

Todavía a inicios del siglo XX, el médico y siquiatra alemán Paul Moebius ${ }^{8}$ afirmó que ciertas porciones del cerebro de suma importancia para la vida mental, tales como las circunvoluciones del lóbulo frontal y temporal, estaban menos desarrolladas en las mujeres desde el nacimiento (Gómez Rodríguez, 2004). Si los científicos afirmaban que la mujer carecía de poder de reflexión y de capacidad para la conciencia y el pensamiento autónomo, no es extraño que las legislaciones de los nacientes estados republicanos la mantuvieran bajo la tutela patriarcal. De esta manera, la ciencia prestó argumentos no sólo para reforzar la inferioridad femenina sino para justificar su reclusión en la esfera doméstica: sin capacidades suficientes para habérselas con lo público, el único rol que les correspondía desempeñar era el de la crianza y cuidado de la especie en la esfera privada. A los argumentos filosóficos y científicos se sumaron importantes elementos del pensamiento católico en torno al rol de las mujeres en aquella sociedad en transición.

La oleada de revoluciones republicanas de 1848 radicalizó las posturas de católicos a favor y en contra de los postulados del liberalismo político. El catolicismo de corte antiliberal tuvo como ideal la restauración integral de los principios cristianos en la vida individual, familiar, social y política. Según el papa Pío IX, su tarea fundamental consistía en "traer a la memoria los principios católicos para que no se desanimaran los países donde seguían en vigor dichos principios ante las concesiones de tipo práctico que se veía obligado a conceder en los países de constitución liberal" (Laboa, 1994, p. 161). En este contexto, la Iglesia católica concibió a la mujer como un contrapoder, una especie de correctivo moral de los hombres para una época de amenazantes cambios:

En el siglo XIX, el alejamiento de la Iglesia y el anticlericalismo, militante o pasivo, son fenómenos exclusivamente masculinos. Los párrocos se lamentan en general: los hombres se van. Su religión no se ha perdido, pero, visiblemente, cambia de situa- 
ción. Deja de ser un hecho global, absoluto, de mentalidad, para asumir los contornos relativos a la opinión religiosa. La "fe" de los hombres se instala en "posiciones políticas". La de la mujer mantiene íntegro el carácter de "hecho de mentalidad" al que los "hechos de comportamiento", más que cualquier otro elemento, imprimen el sello de una fe plena. Por tanto, el catolicismo del siglo XIX se escribe en femenino (de Giorgio, 1993, p. 185).

Según de Giorgio (1993), en este período las mujeres practicaron un contradiscurso fundado en características de una religiosidad sentimental ${ }^{9}$ que extendía la devoción desde la Iglesia hasta la cotidianidad familiar como un ejercicio de soberanía moral en la vida doméstica y sobre la educación de los hijos. El modelo católico reduce a la mujer a los roles de esposa y madre. De las esposas se esperaba sumisión y corrección moral para los maridos increyentes. De las madres, la formación religiosa de los hijos bajo la divisa del ilimitado espíritu de sacrificio.
Si la entrega y el sacrificio eran los pilares que sostenían la identidad de la esposa/madre católica, la mujer no necesitaba aprender mucho, sino todo lo contrario. Para contrarrestar las ideas de la modernidad liberal las mujeres no necesitaban conocimientos sino virtud y carácter. La prensa periódica católica fue la principal difusora de este pensamiento, como muestra este texto publicado en el periódico salvadoreño $L a$ Verdad, en 1871:

\begin{abstract}
¡Ay! de la mujer que extraviándose del camino que le ha trazado el Criador, llega a corromper su corazón por una efímera y falsa educación: se hará ella instrumento ciego del mal que anhelando romper los sagrados vínculos domésticos, civiles y religiosos, quiere valerse de la mujer como de quien puede arruinar la familia en su origen y propagar la depravación entre los pueblos. (Vecchiotti, 13 de mayo de 1871, p. 3).
\end{abstract}

El catolicismo más reaccionario arremetió contra la instrucción intelectual en las mujeres impulsada por los gobiernos de tendencia liberal del siglo XIX. Aduciendo que para la misión asignada por el creador era suficiente la lectura del libro de plegarias, el devocionario o el cate- cismo, la Iglesia católica prohibió la lectura de novelas y de todos aquellos libros que despertaran la imaginación. En su lugar, se prescribieron hagiografías y libros que estimulaban el entusiasmo por los cuidados domésticos, el amor, las virtudes privadas y la religión. 


\section{Debates}

La crítica a la idea de la inferioridad natural de las mujeres no es nueva. Desde los orígenes de la reflexión teórica en Occidente es posible encontrar joyas del pensamiento crítico que son las precursoras de lo que hoy se conoce como feminismo teórico. Según registra la historia crítica de la filosofía, Macrina (320-380 d.C.) fue la primera en cuestionar el paradigma de la inferioridad natural de las mujeres ${ }^{10}$ en medio de uno de los primeros debates filosófico-teológicos del cristianismo naciente. Si Dios había creado al hombre -el ser racional por excelencia- y a la mujer -de naturaleza irracional-, ¿cómo podían ser ambos imagen y semejanza suya? La respuesta de Macrina parte de la premisa de la filosofía griega clásica que afirma que la racionalidad constituye la esencia del alma. En el momento de la creación, dice Macrina, los seres humanos de ambos sexos tenían un cuerpo espiritual, no material. Por tanto, los componentes irracionales como las pasiones y los instintos no formaban parte del alma. Entonces, si la racionalidad estaba en el alma y no en el cuerpo, las mujeres eran tan capaces de ser racionales y de estar libres del influjo de las pasiones como los hombres porque el alma no tenía género. Por tanto, las mujeres y los hombres habían sido creados ambos a imagen y semejanza de Dios (Buss Mitchell, 1998, pp. 128-129).
Aunque las ideas de Macrina fueron compartidas por sus hermanos de sangre -los obispos Basilio el Grande y Gregorio de Nisa-, éstas no lograron modificar en absoluto la estructura jerárquica y patriarcal de la naciente sociedad cristiana. Al contrario, la arraigada tradición patriarcal logró ahogar los ideales igualitarios de aquella religión que luego funcionó como cemento cohesionador de un imperio donde las mujeres fueron excluidas, e incluso perseguidas, si se atrevían a trasgredir los límites establecidos. ${ }^{11}$ Así, el cristianismo se convirtió en el punto de apoyo del orden social medieval.

Sin embargo, en esta larga época de escasa y difícil circulación de las ideas, las iglesias, los conventos y las sedes episcopales se convirtieron en los centros de cultura (Bruzzese y Martino, 1996, pp. 61-62). La proliferación de monasterios, abadías y claustros permitió el acceso de algunas mujeres al conocimiento. Ser monja, amanuense, escribana, bibliotecaria o enseñante fue una alternativa para las mujeres en dos sentidos: por un lado, era una alternativa al rol reproductor asignado por naturaleza; por otro, era una clara posibilidad de acceso al acervo de conocimientos y cultura. 
Pero los conventos no sólo fueron lugar de acceso sino también de producción de conocimiento. MarieLouise von Franz afirma que en la Edad Media "el mundo fantástico del inconsciente era reconocido con mayor claridad que antes" (Franz, 1997, p. 187). Es muy probable que esa claridad esté de algún modo vinculada con el desarrollo de la mística -esa corriente epistemológica más intuitiva que racional- que privilegiaba la experiencia indisolublemente unida a la autoconciencia.

Desde parámetros muy distantes a los de la lógica conceptual griega, el saber místico no buscaba explicar el mundo por la vía conceptual sino experimentarlo por la vía subjetiva. En consecuencia, este modo de conocimiento no se expresó en conceptos ni categorías racionales sino en metáforas, símbolos, alegorías e imágenes. Contrario a la escolástica, la mística no buscaba demostrar la supremacía de la verdad cristiana sino mostrar un camino de iluminación interior para una comprensión más profunda del mundo.

El conocimiento generado por mujeres como Hildegard von Bingen, Matilde de Magdeburgo o Hadewijch de Amberes abarcó no sólo teología sino también música, medicina, literatura y astronomía. ${ }^{12}$ Sus escritos y composiciones enfatizan la idea de un mundo armónico cuyo principio es el amor a toda criatura viviente y donde la dinámica del poder es fuente de vida y no de subordinación.

Algunas de estas mujeres fueron acalladas por la autoridad eclesial bajo la acusación de herejía. Otras, como Margarita Porete, fueron condenadas a morir en la hoguera. Pese a ello, la producción mística medieval abrió la puerta a un nuevo modo de conocimiento que, aunque no fue el más difundido, alimentó la imaginación y la creatividad sin la cual habría sido difícil el desarrollo de las utopías renacentistas. ${ }^{13}$

Entre los siglos $\mathrm{XV}$ y $\mathrm{XVI}$, el Renacimiento constituyó una gradual apertura de los espacios de instrucción para las mujeres. A partir del resurgir del ideal humanístico, las mujeres no sólo tuvieron acceso a la cultura religiosa sino también al arte y, especialmente, a la literatura. De ahí el surgimiento de numerosos ejemplos de mujeres troveras, poetisas y escritoras. Es en este momento donde se sitúa el antecedente más inmediato al feminismo teórico contemporáneo: la llamada querelle des femmes o disputa de las mujeres que se extendió por casi tres siglos. En este debate, por primera vez:

\section{[...] las pensadoras de la Querelle hablaron como mujeres, sin ocultar la diferencia sexual que tan utilizada había sido para denigrarlas; hablaron públicamente desde su experiencia}


personal y de la de otras mujeres del pasado cuya historia se ocuparon de estudiar. Al hablar en estos términos, rechazaron las reglas de juego tradicionales y abrieron un proceso de crítica al conocimiento que los filósofos y teólogos del pasado habian elaborado sobre ellas. (Rivera, 2000, p. 615).

La disputa inició hacia el año 1400, cuando Christine de Pizan respondió a los argumentos que Guillaume de Lorris expuso en el Roman de la rose, publicado alrededor de 1225. De Pizan calificó estas ideas como misóginas, condenatorias e insultantes para las mujeres. Como continuación a la querella, de Pizan publicó en 1405 Le livre de la Cité des dames. ${ }^{14}$ El tema central de la obra es la condición de inferioridad de las mujeres como resultado de la superioridad del poder masculino en la época. Con la misma alegoría que usara Agustín de Hipona en La ciudad de Dios, Christine de Pizan construye una ciudad utópica en la que las mujeres ilustres y virtuosas de la historia habitarán bajo la

protección del derecho, la justicia y el poder. ${ }^{15}$ Según Victoria Cirlot, esta obra permite ver por primera vez que una mujer "se levanta en contra de la tradición masculina para crear una conciencia de género" (Cirlot, 2013, p. 11). Y lo hace a partir de la recopilación de historias de mujeres cuyas actuaciones se distanciaron del modelo femenino sustentado por el sentido común milenario.

Dos siglos más tarde, la italiana Lucrecia Marinella examinó el tema central de la querelle en un tratado titulado La nobiltá et l'eccellenza delle donne co' diffetti et mancamenti de gli huomini. ${ }^{16}$ Marinelli también arremete contra quienes sostenían la inferioridad natural de las mujeres:

Pero si aquellas tienen la misma alma racional que el hombre, como antes he mostrado claramente, e incluso más noble, ¿por qué no pueden aprender aún con mayor perfección las mismas artes y ciencias que los hombres? Así, las pocas que acceden a las doctrinas llegan a distinguirse tanto en las ciencias que los hombres las envidian, o las odian, como suelen odiar los menores a los mayores. (Rius Gatell, 1997, p. 131).

Ya en medio del movimiento de la Ilustración, fue la francesa Marie de Gournay ${ }^{17}$ la que reivindicó la igualdad de los sexos en una obra titulada Egalité des hommes et des

femmes. En la obra, la autora argumenta también sobre el valor e influencia de la educación en las mujeres: 
Si las damas llegan más raramente que los hombres a los grados de excelencia, es maravilla que esta falta de buena educación, $e$ incluso la influencia de la mala expresa y profesa no sea peor, y que no les impida poder llegar del todo. (Otero Vidal, 1997, p. 86).

La idea de la reivindicación de la igualdad de los sexos también estuvo presente en el Virreinato de la Nueva España. ${ }^{18}$ No cabe duda que los conflictos que enfrentó sor Juana debido a su "poderosa inclinación a las letras" permiten ubicarla en esta misma corriente de reivindicación del pensamiento femenino. De esto da cuenta su célebre Respuesta de la poetisa a la muy ilustre sor Filotea de la Cruz (1691), donde la monja expone:

El escribir nunca ha sido dictamen propio, sino fuerza ajena; que les pudiera decir con verdad: Vos me escogisteis. Lo que si es verdad que no negaré (lo uno porque es notorio a todos, y lo otro porque, aunque sea contra mí, me ha hecho Dios la merced de darme grandísimo amor a la verdad) que desde que me rayó la primera luz de la razón, fue tan vehemente y poderosa la inclinación a las letras, que ni ajenas reprensiones -que he tenido muchas-, ni propias reflejas -que he hecho no pocas-, han bastado a que deje de seguir este natural impulso que Dios puso en mi entendimiento dejando solo lo que baste para guardar su Ley, pues lo demás sobra, según algunos, en una mujer; y aún hay quien diga que daña. (De la Cruz, 1977, p. 830).

Desde el siglo XVI, la Reforma protestante había marcado una ruptura definitiva de la unidad religiosa, política y cultural de la Europa medieval. La popularización de la lectura de la Biblia obligó a generar un mayor acceso de las mujeres a los procesos de alfabetización. Simultáneo a este proceso, en París y en otras grandes ciudades proliferaron centros de intensa actividad intelectual en los "salones" de las casas aristocráticas. Los más importantes y famosos salones del siglo XVIII fueron animados por mujeres, en palacios de su propiedad. A ellos asistían filósofos, científicos y literatos de la época, con quienes estas mujeres discutían las ideas en boga. De estos salones derivó el movimiento literario femenino conocido como "preciosismo", cuyas prácticas contribuyeron a visibilizar la capacidad intelectual de las mujeres (Martino y Bruzzese, 1996).

Sin la existencia de los salones no se puede entender la obra del francés Poulain de la Barre (1647-1723), 
quien continuó la línea del debate iniciado en la querelle des femmes. De la Barre escribió una obra titulada De l'education des dames pour la conduite de l'esprit dans les sciences, et dans les moeurs, ${ }^{19}$ que fue publicada en 1674 . Noventa años antes que el Emilio de Rousseau, de la Barre deja clara su postura con respecto a la igualdad natural entre varones y mujeres:

Después de mostrar a las mujeres que no existe nada grande de lo que ellas no sean tan capaces como los varones, me ha parecido que no basta señalarles cómo alcanzar, igual que ellos, los más elevados conocimientos. Es también necesario apoyar los razonamientos que la filosofía me ha proporcionado, con un ejemplo suficientemente notorio para establecer la verdad que he defendido y animarlas para que emprendan algo tan ambicioso como lo que les propongo. (De la Barre en Cazés Menache, 2007, p. 9).

De la Barre, quien fue discípulo rencias del cuerpo no bastaban para de Descartes, sostuvo que la inteli- legitimar ningún tipo de desigualdad: gencia no tiene sexo y que las dife-

Estas conversaciones están dedicadas a una joven muy inteligente que tiene el propósito de dedicarse al estudio. Se dan a conocer pensando en todas las mujeres que se hallan en disposición similar. Por ello se titulan Educación de las mujeres, aunque no son menos útiles para los hombres, pues las obras dirigidas a ellos sirven igualmente para las mujeres: no hay más que un método para instruir a unos y a otras siendo como son de la misma especie. (De la Barre en Cazés Menache, 2007, p.12).

Uno más de este grupo de ilustrados que reivindicó la igualdad de mujeres y varones fue Nicolás de Condorcet. En 1790, el filósofo francés escribió un alegato en el que denunciaba que la exclusión de las mujeres de los derechos de ciudadanía era resultado de prácticas sociales que habían naturalizado la subordinación femenina. Si las mujeres no reclamaban el derecho natural que tenían era porque la práctica social imperante les había impedido tomar conciencia de ello.

En su obra Cinco memorias sobre la instrucción pública, de 1791, Condorcet reconoce la igualdad de capacidades intelectuales en las mujeres: 
En cuanto a las ciencias, ¿por qué deberían estarles prohibidas? Aun cuando las mujeres no pudieran contribuir a sus progresos por sus hallazgos, ¿por qué aquellas mujeres cuya vida no ha de llenarse por el ejercicio de una profesión lucrativa y no puede cumplirse enteramente con las ocupaciones domésticas no podrían trabajar útilmente para el aumento de las luces, ocupándose de las observaciones que exigen una exactitud casi minuciosa, una gran paciencia, una vida sedentaria y reglada? Quizá hasta serían más aptas que los hombres para dar método y claridad a los libros elementales [...] (Condorcet, 2001, p. 110).

Según el filósofo, era nece- la instrucción pública (Condorcet, sario que las mujeres compartieran 2001, p. 111). Este planteamiento la misma instrucción dada a los hombres por cuatro razones fundamentales: para vigilar la educación de los hijos; para no perpetuar la desigualdad en las familias por causa de la falta de instrucción de la mujer; para conservar los conocimientos de sus maridos; y para mostrar que las mujeres tenían el mismo derecho que los hombres a apuntaba a masificar la instrucción pública como fundamento del nuevo orden social inaugurado con la Revolución francesa. Sin acceso a la instrucción, las mujeres no estarían en condiciones de participar en la dinámica de la democracia moderna. Según Sonsoles San Román (2006), Condorcet entendía que:

\begin{abstract}
[...] los derechos naturales de hombres y mujeres son inalienables y anteriores al Estado; razón suficiente para que éste garantice, mediante una igual instrucción pública, el desarrollo de las disposiciones naturales de ambos sexos. Condorcet da un paso decisivo. $Y$ va más allá. Por supuesto que hombres y mujeres presentan diferencias notables, pero el origen de tales desigualdades se encuentra en el proceso de socialización al que hombres y mujeres han sido sometidos (p. 38).
\end{abstract}

Aunque los ideales de libertad, igualdad, fraternidad comenzaban a cuestionar las bases del antiguo régimen patriarcal, las instituciones no cambiaron inmediatamente. Incluso la declaración de los Derechos del hombre y del ciudadano, de agosto de 1789 , dejó fuera a las mujeres. En
1791, Olympia de Gouges ${ }^{20}$ intentó remediar esa exclusión con el texto que proclama la Declaración de los derechos de la mujer y de la ciudadana, donde afirma que "La mujer nace libre y permanece igual al hombre en derechos" (de Gouges en Puleo, 1993, p. 156). 
Un año después, la filósofa britá- Wollstonecraft como "la crítica más nica Mary Wollstonecraft ${ }^{21}$ publicó directa a la pedagogía del Emilio y su obra titulada Vindicación de los el intento más radical de desenmasderechos de la mujer. En esta obra carar la lógica rousseauniana" (Fuster contesta la tesis rousseauniana García, 2007, p. 10). Así, en relación de la inferioridad natural de las con la opinión prevaleciente de un mujeres y señala las diferencias carácter sexual como fundamento educativas como causa principal de de la diferencia de los géneros, la la desigualdad entre ambos sexos. autora afirma: Algunos han señalado la obra de

Con el fin de explicar la tiranía de los hombres y excusarla, se han esgrimido muchos argumentos ingeniosos para probar que los dos sexos, en la adquisición de la virtud, deben apuntar a alcanzar un carácter muy diferente; o, para hablar de modo más explícito, no se admite de las mujeres que tengan la suficiente fortaleza mental para adquirir lo que realmente merece el nombre de virtud. No obstante, al admitir que tienen almas, debería parecer que solo hay un camino dispuesto por la Providencia para dirigir a la humanidad a la virtud o a la felicidad. Luego, si las mujeres no son enjambres de frívolas efímeras, ¿por qué hay que mantenerlas en la ignorancia bajo el nombre engañoso de la inocencia? (Wollstonecraft, 2000, $p$. 127).

A partir de esta constatación, las oportunidades educativas para Wollstonecraft insiste en igualar hombres y mujeres:

Para hacer al género humano más virtuoso y, por supuesto, feliz, ambos sexos deben actuar desde los mismos principios. ¿Pero cómo puede esperarse esto, cuando solo se permite a uno considerar si resultan razonables? Para hacer también realmente justo el pacto social, y para extender los principios ilustrados que solo pueden mejorar el destino del hombre, debe permitirse que las mujeres fundamenten su virtud sobre el conocimiento, lo que apenas es posible si no se las educa mediante las mismas actividades que a los hombres. (Wollstonecraft, 2000, p. 363).

Estas ideas también fueron Karl Christian Krause. En El Ideal de compartidas por el filósofo alemán la Humanidad. Un ensayo, ${ }^{22}$ publicado 
en 1811, Krause desarrolla una teoría social basada en la conformación de dos tipos de esferas: las básicas de vida (persona, familia y pueblos) y las esferas para la realización de los fines racionales humanos (religión, derecho, ciencia, arte y educación). Estas esferas de carácter autónomo se enlazan armónicamente para crear la "Alianza de la Humanidad", cuya finalidad era velar por el fomento de lo puramente humano a partir de una interrelación dinámica y armónica (Colmenares, 2009, p. 204).

Lo peculiar de la teoría krausista es que no sólo fundamenta una nueva manera de organizar el poder y las interacciones entre los distintos ámbitos de la sociedad sino que cuestiona los fundamentos del sistema patriarcal:

\begin{abstract}
Varón y mujer son igualmente esenciales en la Humanidad, y por tanto la mujer no está subordinada al varón bajo ningún punto de vista. La mujer es en todas las capacidades del espíritu y del ánimo tan capaz y tan original con respecto a todas las partes del destino humano como el varón. El género femenino es tan capaz de una formación omnivalente, específica y armónica como el masculino; y la Humanidad misma permanecerá deficiente, y sólo configurada a medias, en tanto que el género bello y más débil de la mujer -sometido desgraciadamente y sin escrúpulo por la fuerza bruta de los varones- tenga que permanecer postergado con respecto al varón en cualquier aspecto del destino humano. (Krause en Ureña, 2005, p. 29).
\end{abstract}

Arturo Andrés Roig subraya que 58). Krause afirma que si el Estado el pensamiento krausista alcanza a democrático provenía de la familia, cuestiones de tanto peso como la del era fundamental reformular esta origen del Estado y su conformación estructura sobre nuevas bases dadas como poder político (Roig, 2007, p. por los valores de libertad e igualdad:

Esta mitad esencial de la humanidad está hoy en unos pueblos oprimida y degradada, en otros postergada o abandonada en su educación por el varón, que hasta ahora se ha atribuido una superioridad exclusiva, cuando observa que la mujer dista hoy mucho del claro conocimiento de su destino en el todo, de sus derechos y funciones y altos deberes sociales. (Krause, 1860, p. 93).

Roig (2007) ${ }^{23}$ demuestra que el más fuertes argumentaciones que filósofo alemán desmontó dos de las sostenían la condena de la mujer a 
la vida privada. Por un lado, la condición de madre; por el otro, la noción de ámbito privado. Según Krause, la maternidad no define a la mujer en cuanto a ser humano por lo mismo que su humanidad está antes que esta condición. En cuanto al ámbito privado, Krause argumentó que debía ser valorado como una conquista de la humanidad y no como el lugar exclusivo de las mujeres condenadas a la domesticidad.

Todas estas ideas filosóficas que contestaron el pensamiento de la inferioridad natural femenina formaron la corriente crítica de la Ilustración a la que María José Lacalzada (2005) Llama humanismo ilustrado-liberal. Críticos a cualquier forma de dominación, estos intelectuales abogaron por la igualdad de oportunidades "extendiendo cada vez a un mayor número las posibilidades de instrucción intelectual y educación moral" (Lacalzada, 2005, p. 215). Por ello, es bastante acertado situar el origen del feminismo teórico en el marco del movimiento cultural de la Ilustración a finales del siglo XVIII. Este "hijo no querido del igualitarismo ilustrado", como lo llama Celia Amorós (1985), radicalizó los principios del movimiento de las luces y proporcionó una perspectiva para evaluar sus propios presupuestos.

Aunque el siglo XIX fue escenario de la transformación de la educación femenina a través de la consolidación de los sistemas de instrucción pública, ${ }^{24}$ esta apuesta no alcanzó para lograr su incorporación plena a la dinámica política de la democracia moderna. De ahí que la lucha de las mujeres por la ciudadanía -que comenzó durante la Revolución francesa y continuó con el movimiento sufragista- y la apuesta por generar la participación de las mujeres en los asuntos públicos constituyen una primera ola del feminismo como movimiento social. Pese a que ni el movimiento de la Ilustración ni las revoluciones republicanas lograron borrar siglos de prejuicios y de tradición patriarcal, ${ }^{25}$ estos acontecimientos sí constituyen un parteaguas en la historia del pensamiento feminista.

A mediados del siglo XX, el desarrollo del feminismo teórico tuvo un enorme impulso con la publicación del ensayo $E l$ segundo sexo, de Simone de Beauvoir. La obra proporcionó fundamentación filosófica a las posiciones defensoras de la emancipación femenina y desmontó varios discursos en torno a la feminidad. Hacia 1960, el feminismo como perspectiva teórica y movimiento social amplió "la concepción del modo por el que un sistema de poder se mantiene y reproduce" (Amorós y De Miguel, 2005, p. 71). Esta segunda ola del feminismo reivindicó la politización de la esfera privada a partir del lema "lo personal es político" que surgió de la obra Política sexual de Kate Millet en 1969. 
A partir de la década de 1980, una tercera ola del feminismo evidenció que la superación de las discriminaciones legales en las sociedades democráticas no había conseguido un cambio significativo en la situación comparativa entre los sexos. Esta constatación orientó las reivin- dicaciones hacia la superación de la desigualdad de las mujeres respecto a los varones en el acceso a la esfera pública; no bastaba con estar presentes en lo público, también había que lograr equidad en la distribución de los recursos, del poder y del reconocimiento.

\section{Voces salvadoreñas}

En El Salvador, la incidencia de grupos de mujeres en los asuntos públicos ha sido registrada desde comienzos del siglo XIX (Vásquez Monzón, 2014). Sin embargo, la reflexión sistemática e intencionada en torno a las concepciones que sustentan las desigualdades e inequidades entre los géneros no emergió sino hasta en la década de 1990 por impulso del movimiento feminista. La reflexión inició a partir de la experiencia de algunas excombatientes; aun cuando el conflicto armado las obligó a aceptar roles no tradicionales, una vez acabada la guerra, sus propias organizaciones intentaron desplazarlas de nuevo hacia el ámbito privado y despojarlas del protagonismo y la autoridad ganada en aquel tiempo de excepción.

En la búsqueda por "desmilitarizar y despatriarcalizar sus propias estructuras" (Navas, 2011, p. 63), la toma de conciencia sobre la permanencia de las desigualdades en un movimiento que enarboló la bandera de la liberación sentó las bases para una reflexión orientada a democratizar las relaciones entre los géneros en todas las estructuras de convivencia: "la conciencia de las innumerables irregularidades que genera el poder patriarcal es lo que caracteriza al movimiento feminista" (Martínez Castro, 2011, p. 23). De ahí que es posible afirmar que la incorporación de la categoría patriarcado al análisis de las relaciones de poder marcó el nacimiento del pensamiento feminista en El Salvador.

Estos primeros pasos del feminismo teórico salvadoreño están enmarcados en la corriente de estudios alimentados por el modelo conceptual de historia de las mujeres, desarrollado en Europa y en América Latina en las últimas décadas del siglo XX. Los historiadores franceses Georges Duby y Michelle Perrot definieron este modelo como "una historia de relaciones que pone sobre el tapete la sociedad entera, que es historia de las relaciones entre los sexos y, en consecuencia, también es historia de los hombres" (Duby y Perott, 1993, p. 7). En Perú, 
desde 1998, el Centro de Estudios de la Mujer en la Historia de América Latina (CEMHAL) se propuso fomentar el estudio de la historia desde una perspectiva de género y promover el campo de estudio interdisciplinario de la historia de las mujeres en Latinoamérica.

En mayo de 2007, la Universidad de El Salvador creó el Centro de Estudios de Género con el objetivo de asesorar la incorporación del enfoque de género a los procesos de formación académica y a las investigaciones desarrolladas en la universidad. Desde el año 2010, la carrera de Licenciatura en Historia de la Universidad de El Salvador introdujo el estudio sobre el tema de género a través de seminarios de investigación dedicados a la historia de las mujeres. Este modelo conceptual de historia permitió reflexionar "proponiendo el concepto de género como principal articulador teórico en las relaciones sociales" (Viegas Guillem, 2013, p. 17) y generar una mayor visibilidad de las prácticas y discursos de las mujeres en distintos ámbitos.

Sin lugar a duda, las categorías de patriarcado y género heredadas del feminismo teórico han resultado reveladoras no sólo para el estudio del pasado sino también para el análisis de otros ámbitos de la realidad salvadoreña actual. Jaime Rivas Castillo constata que, en los estudios sobre migración, "tomar en cuenta la diferenciación de género implica reconocer que hombres y mujeres presentan motivaciones diferentes para emigrar, a la vez que experimentan de manera distinta la decisión, la forma de viajar, las rutas y los riesgos" (Rivas Castillo, 2013, p. 218). Sin embargo, el hecho de que una mujer migrante sea indígena o mestiza, de zona rural o zona urbana, agricultora o trabajadora sexual, exige una mayor complejidad en el análisis y deja en evidencia la insuficiencia de las categorías de patriarcado y género.

De ahí que Laura Aguirre ponga en evidencia los límites del discurso feminista radical que homogeneizó a las mujeres en la categoría de víctimas del poder patriarcal. Aguirre explica que el riesgo de esta vertiente del feminismo es que oscurece las complejidades de espacios configurados no sólo por el patriarcado sino también por relaciones de raza, clase y nacionalidad. Desde la perspectiva crítica del feminismo, la socióloga insiste en superar las explicaciones simplistas donde las mujeres quedan reducidas a seres pasivos, necesitados de intervención y carentes de toda agencia y exhorta a complejizar el análisis para evidenciar "las relaciones de poder estatales, capitalistas, patriarcales y raciales, en intersección con las acciones y deseos de las mujeres y sus estrategias y sobrevivencias de vida" (Aguirre, 2012, p. 22). 
Ya los feminismos poscoloniales ${ }^{26}$ habían evidenciado la insuficiencia de las categorías de patriarcado y género para analizar las múltiples problemáticas que enfrentan los sujetos subordinados al modelo cultural hegemónico. De ahí que la incorporación de la categoría de interculturalidad, por ejemplo, ha permitido hacer visibles "las identidades individuales y colectivas en cada cultura, las cuales expresan también una demanda universal" (Klesing-Rempel, 2003, p. 149). Como señala Raúl Fornet-Betancourt (2001): "La cuestión no es ahora cómo integrar lo propio en el movimiento de lo universal sino cómo injertar la diversidad del mundo en lo propio" (p. 65). No cabe duda que la eterna tensión entre lo particular y lo universal es un elemento fundamental para complejizar el análisis sobre las relaciones de poder.

\section{Vislumbres}

Todo lo que se presenta a nosotros, en el mundo social-histórico, está indisolublemente tejido a lo simbólico. Los actos reales, individuales o colectivos - el trabajo, el consumo, la guerra, el amor, el parto-, los innumerables productos materiales sin los cuales ninguna sociedad podría vivir un instante, no son (ni siempre ni directamente) símbolos. Pero unos y otros son imposibles fuera de una red simbólica (Castoriadis, 1983, p. 201).

La producción teórica feminista refleja un esfuerzo por responder a la complejidad de una realidad que estalla las categorías conceptuales y demanda la permanente revisión y ampliación de los marcos de interpretación de la misma. Sin embargo, la tarea ahora es, por un lado, trascender ese carácter reactivo de reafirmación intelectual que criticó Riane Eisler en 1992; y, por otro lado, proponer pistas para la transformación de la cultura patriarcal desde las subjetividades, como señaló Carosio en 2012.
Desde finales del siglo XIX, pensadores como Nietzsche, Freud y Jung advirtieron sobre los riesgos de pensar al ser humano y a la sociedad al margen del inconsciente. A lo largo del siglo XX, muchas otras voces ${ }^{27}$ pusieron en evidencia la necesidad de superar la escisión entre lógica e imaginación heredada del pensamiento griego y consolidada en la Modernidad. Lluís Duch y Albert Chillón (2012) advierten sobre el peligro de este reduccionismo cuando señalan que, tanto el monismo lógico -culmen de la ilustración y el concepto- como el mítico -culmen del romanticismo y la imagen- desembocan en la falacia 
de que logos y mythos - cada uno por sí mismo-pueden expresar de modo

exclusivo y exhaustivo la condición humana:

\begin{abstract}
[...] el homo no es solo sapiens, si por tal entendemos "lógico" y "racional" por excelencia o en exclusiva. Por más que el maximalismo racionalista en que la Ilustración incurrió haya generalizado tal creencia, es preciso resaltar el papel cardinal que el mythos -imaginación, afectividad, relato, sensibilidad, emoción-cumple en la existencia humana en todo lugar y tiempo. (Duch y Chillón, 2012, p. 31).
\end{abstract}

Es pertinente recordar que el modelo teórico que privilegia la dimensión lógica sobre la imaginativa hunde sus raíces en el esquema jerárquico de dominación que considera superior el saber conceptual frente al saber imaginativo. A lo largo de la historia, la supremacía de lo explícito sobre lo implícito, lo científico sobre lo vivencial, la unicidad del signo sobre la polisemia del símbolo ha generado violentas confrontaciones no sólo de palabras sino de hechos hasta llegar a extremos como el exterminio de lo distinto. ${ }^{28}$ La alternativa a este modelo de dominación jerárquica, según Riane Eisler (1992), es la de un modelo de organización social coparticipativa, cuyo principio fundante sea la conexión en vez de la jerarquía, donde la diversidad no se equipara a la inferioridad o a la superioridad y cuyos valores principales son la compasión y la no violencia.

No hay que perder de vista que las instituciones son redes simbólicas socialmente sancionadas en las que se combinan dos componentes: uno funcional y uno imaginario (Castoriadis, 1983). En el momento en que un colectivo social no reconoce el componente imaginario de las instituciones es cuando se produce la alienación. En otras palabras, una sociedad está alienada cuando olvida que sus instituciones son producto de su propio imaginario y, por tanto, son susceptibles de transformación (Castoriadis, 1983, p. 229). De ahí que el autor asigne a lo imaginario un papel radical de creación en la historia como reveladora de los límites de la razón.

Hace falta, entonces, lo que la teóloga Sallie MacFague (1994) llamó un "constructo imaginativo verosímil" (p. 67), es decir, un entramado de sentidos, imágenes y relatos que apunten a transformar las relaciones de convivencia cotidiana a partir de tres elementos: la identificación (y no la negación) de los conflictos vinculados a las nociones de sexualidad y género; el reconocimiento de los valores, creencias e ideas que están en la base de los distintos colectivos sociales; y la negociación de sentidos/ 
significados desde la convivencia cotidiana en función del bien común. Para ello será necesario recurrir al saber intuitivo que privilegia la experiencia de la convivencia más que la uniformidad discursiva. Más que diferenciar los opuestos - como suele hacer la lógica conceptual- "este saber fomentaría las energías complemen- tarias dentro de cada alma humana; armonizaría los dos modos de pensar -analítico y analógico-; y los dos polos del universo -la materia y el espíritu-" (Suki Colegrave, 1994, p. 47).

Desde hace casi medio siglo, Joseph Campbell $^{29}$ vislumbró esta tarea:

\begin{abstract}
Los viejos modelos ya no funcionan; los nuevos aún no han aparecido. De hecho, somos nosotros mismos los que ahora estamos dando forma a lo nuevo al modelar nuestras interesantes vidas. Y tal es el sentido (en términos mitológicos) del desafío presente: somos los "antepasados" de una edad por venir, los generadores involuntarios de los mitos en los que se sustentará esa nueva edad, los modelos míticos que inspirarán a las vidas venideras. En un sentido muy real, por lo tanto, el actual es un momento de creación (Campbell, 2013, p. 18).
\end{abstract}

Más que las ideas convencen las historias compartidas. Más que los argumentos, mueven los relatos que se enganchan en los afectos y despiertan compasión y empatía con la alteridad aún a pesar de los prejuicios. Más que confrontar conceptos y categorías, urgen utopías que imaginen mundos cotidianos en un nuevo modelo de relaciones. Más que superhéroes o liderazgos mesiánicos, son vitales las voces de los múltiples colectivos sociales que, desde lo cotidiano, construyen resistencias creativas para desmontar el poder hegemónico a partir del humor, el juego y el placer. 


\section{Referencias bibliográficas}

- Aguirre, L. (2012). Trata de mujeres, prostitución y migración: las trampas del discurso dominante. Identidades revista de Ciencias Sociales y Humanidades ( $\left.\mathrm{N}^{\circ} .5\right)$, pp. 11-28.

- Álvarez,S. (2008a). Diferencia y teoría feminista. En Beltrán, E. y Maquieira, V. (Eds.). Feminismos, debates teóricos contemporáneos (pp. 243-283). Madrid: Alianza Editorial.

. (2008b). Feminismo radical. En Beltrán, E. y Maquieira, V. (Eds.). Feminismos, debates teóricos contemporáneos (pp. 104-115). Madrid: Alianza Editorial.

- Amorós, C. (1985). Hacia una crítica de la razón patriarcal. Barcelona: Anthropos.

- Amorós, C. y de Miguel, A. (Eds.). (2005). Teoría feminista: de la llustración a la globalización 1. Madrid: Minerva Ediciones.

- Burdiel, I. (2000). Introducción. En Wollstonecraft, M. Vindicación de los derechos de la mujer. Madrid: Ediciones Cátedra.

- Buss Mitchell, H. (1998). Raíces de la sabiduría. México: International Thompson Editores.

- Campbell, J. (2013). Diosas. Girona, España: Ediciones Atalanta.

- Carosio, A (Coord.). (2012). El feminismo y cambio social en América Latina y el Caribe. Buenos Aires: CLACSO.

- Castoriadis, C. (1983). La institución imaginaria de la sociedad. Barcelona: Tusquets Editores.

- Cazés Menache, D. (2007). Obras feministas de Fracois Poulain de la Barre (1647-1723). Tomo III. México: UNAM, Centro de Investigaciones Interdisciplinarias en Ciencias y Humanidades.

- Cirlot,V.(2013). Cristina de Pizán. La ciudad de las damas. Madrid: Ediciones Siruela.

- Coba, L. y Herrera, G. (2013). Nuevas voces feministas en América Latina: ¿continuidad, rupturas, resistencias? Íconos. Revista de Ciencias Sociales (No. 45), pp. 17-23.

- Cobo, R. (1995). Fundamentos del patriarcado moderno. Jean Jaques Rousseau. Madrid: Ediciones Cátedra.

- Colegrave, S. (1992). El desarrollo del principio femenino en la conciencia humana. En Zweig, C. (Ed.) Ser mujer (pp. 40-52). Barcelona: Editorial Kairós. 
- Colmenares, K. (2009). El krausismo. En Dussel, E. y otros, El pensamiento filosófico latinoamericano, del Caribe y latino (1300-2000). (pp. 203-210). México D.F.: Siglo XXI Editores.

- Comte, A. (1998). La filosofía positiva. México D. F.: Editorial Porrúa.

- Condorcet, N. (2001). Cinco memorias sobre la instrucción pública y otros escritos. Madrid: Ediciones Morata.

- De Giorgio, M. (1993). El modelo católico. En Duby, G., y Pierrot, M., dir., Historia de las mujeres. El siglo XIX: La ruptura política y los nuevos modelos sociales. Madrid: Taurus, pp. 183-217.

- De la Cruz, J. I. (1977). Obras completas. México D.F.: Editorial Porrúa.

- Duby, G. y Perrot, M. (Dir.). (1993). Historia de las mujeres. El siglo XIX. La ruptura política y los nuevos modelos sociales. Madrid: Tauros Ediciones.

- Duch, L. y Chillón, A. (2012). Un ser de mediaciones. Antropología de la comunicación Vol. 1. Barcelona: Herder Editorial.

- Eisler, R. (1992). La transformación social y lo femenino: de la dominación a la colaboración solidaria. En Zweig, C. Ser mujer (pp. 53-71). Barcelona: Editorial Kairós.

- Franz, M. L. (2017). El proceso de individuación. En Jung, C. y otros. El hombre y sus símbolos. (pp. 158-229). Barcelona/Buenos Aires: Paidós.

- Fornet-Betancourt, R. (2001). Transformación intercultural de la filosofía. Bilbao: Desclée de Brower.

- Fuster García, F. (2007). Dos propuestas de la Ilustración para la educación de la mujer: Rousseau versus Mary Wollstonecraft. A Parte Rei. Revista de Filosofía ( $\left.\mathrm{N}^{\circ} 50\right)$, pp. 1-10)

- Gómez Rodríguez, A. (2004). La estirpe maldita. La construcción científica de lo femenino. Madrid: Minerva.

- Klesing-Rempel, U. (2003). Relaciones de poder, construcción genérica e interculturalidad. En Fornet-Betancourt, R. (Ed.). Culturas y poder. Interacción y asimetría entre las culturas en el contexto de la globalización (pp. 141-150). Bilbao: Desclée de Brower.

- Krause, C. (1860). Ideal de la humanidad para la vida, con introducción y comentarios por d. Julián Sanz del Río. Madrid: Imprenta de Manuel Galiano.

- Küng, H. (2002). La mujer en el cristianismo. Madrid: Trotta.

- Laboa, J. M., (1994). La iglesia del siglo XIX. Entre la Restauración y la revolución. Madrid: Publicaciones de la Universidad de Comillas.

- Lacalzada de Mateo, M.J.(2005). Humanismo ilustrado-liberal en la emancipación de las mujeres y su engranaje masónico en España. En Amorós, 
C. y de Miguel, A. (Eds.). Teoría feminista: de la Ilustración a la globalización 1 (pp. 211-243). Madrid: Minerva Ediciones.

- MacFague, S. (1994). Modelos de Dios. Madrid: Sal Terrae.

- Maquieira, V. (2008). Género, diferencia y desigualdad. En Beltrán, E. y Maquieira, V. (Eds.). Feminismos debates teóricos contemporáneos (pp. 127-189). Madrid: Alianza Editorial.

- Martínez Castro, F. (2011). Notas sobre el feminismo en El Salvador. Cultura revista de la Secretaría de Cultura de la Presidencia ( $\mathrm{N}^{\circ}$. 106), pp. 21-25.

- Martino, G. y M. Bruzzese (1996). Las filósofas. Madrid: Ediciones Cátedra.

- Moebius, P. (1900). La inferioridad mental de la mujer. Valencia: F. Sempere.

- Morant Deusa, I. (1997). ¿Qué es una mujer? O la condición sentimental de la mujer. En Rodríguez Magda, R. (Ed). Mujeres en la historia del pensamiento (pp. 145-165). Barcelona: Anthropos.

- Navas, M. C. (2011). De guerrilleras a feministas: elementos para estudiar las organizaciones de mujeres en El Salvador, 1992-1995. Revista Cultura (No.106), pp. 55-68.

- Otero Vidal, M. (1997). Christine de Pizan y Marie de Gournay. Las mujeres excelentes y la excelencia de las mujeres. En Rodríguez Magda, R. (Ed.). Mujeres en la historia del pensamiento (pp. 77-93). Barcelona: Anthropos.

- Perrot, M. (2011). Historia de las alcobas. México, D.F.: FCE/Siruela.

- Puleo, A. (1993). La llustración olvidada. La polémica de los sexos en el siglo XVIII: Condorcet, De Gouges, De Lambert y otros. Madrid: Anthropos.

- Ratto, C. (2002). Sor Juana Inés de la Cruz y Carlos de Sigüenza y Góngora en el episodio novohispano de la «querella de las mujeres». En Meyer, A. (Coord.). Carlos de Sigüenza y Góngora. Homenaje 1700-2000, Vol. II (pp. 151-177). México: UNAM.

- Rius Gatell, R. (1997). De las mujeres memorables en Lucrezia Marinelli: nobleza y excelencia en la Venecia de 1600. En Rodríguez Magda, R. (Ed). Mujeres en la historia del pensamiento (pp.113-144). Barcelona: Anthropos.

- Rivas Castillo, J. (2013). Situación de las mujeres migrantes salvadoreñas en el Soconusco, Chiapas. En Viegas Guillem, J. (Comp.) Historias de mujeres, mujeres de historia en El Salvador (pp. 213-241). San Salvador: Dirección Nacional de Investigaciones en Cultura y Arte.

- Rivera, M.M. (2000). El cuerpo femenino y la "querella de las mujeres" (Corona de Aragón, siglo XV). En Duby, G. y Perrot, M. (Dirs.). Historia de las mujeres 2. La Edad Media (pp. 593-605). Madrid: Santillana Ediciones. 
- Roig, A. (2007). Cuestiones de dialéctica y género en Krause. Sofía o la nueva mujer. Estudios de Filosofía Práctica e Historia de las Ideas, Año 8 (No. 9), pp. 57-72.

- San Román, S. (2006). Las primeras maestras. Barcelona: Editorial Ariel.

- Shopenhauer, A. (1998). El amor, las mujeres y la muerte. Barcelona: Edicomunicación,

- Ureña, E. (2005). Krausistas, frobelianos y la cuestión de la mujer. En Álvarez, P. y Vázquez-Romero, J. M. (Eds). Krause, Giner y la Institución Libre de Enseñanza. Nuevos estudios (pp. 27-51). Madrid: Universidad Pontificia de Comillas.

- Valle Ferrer, N. (2010). Educación y feminismo en la obra de Eugenio María de Hostos. Revista del Instituto de Cultura puertorriqueña Año 9 ( $\mathrm{N}^{\circ}$ 19), pp. 76-81.

- Vásquez Monzón, O. (2006). Cristologías liberadoras, una aproximación al pensamiento de Jon Sobrino y Elisabeth Schüssler. Realidad. Revista de Ciencias Sociales y Humanidades (N. 110), pp. 585-614. . (2014). Mujeres en público, el debate sobre la educación femenina entre 1871 y 1889. San Salvador: UCA Editores.

- Vecchiotti, M. (13 de mayo de 1871). Discurso pronunciado por el Señor Canónigo Penitenciario Doctor Don Miguel Vecchiotti el 30 de abril próximo pasado en el acto de inaugurarse la escuela de niñas pobres fundada por las Hermanas de la Caridad. La Verdad, p. 3.

- Viegas Guillem, J. (Comp.). (2013). Historias de mujeres, mujeres de historia en El Salvador. San Salvador: Dirección Nacional de Investigaciones en Cultura y Arte.

- Wollstonecraft, M. (2000). Vindicación de los derechos de la mujer. Madrid: Ediciones Cátedra.

- Zemon Davis, N. y Farge, A. (2000). Introducción. En Duby, G. y Perrot, M. (Dir). Historia de las mujeres 3. Del renacimiento a la Edad Moderna. Madrid: Santillana Ediciones. 


\section{Notas}

1 Grupo "Feminismo y cambio en América Latina y el Caribe” en el que participaron investigadoras de Chile, México, Cuba, Costa Rica, Venezuela y Argentina. Los textos debatidos en el primer encuentro de este grupo están reunidos en el libro Feminismo y cambio social en América Latina publicado en 2012.

2 Este campo de investigación interdisciplinario explora las formas de creación y difusión de significados sociales a partir del análisis de las múltiples relaciones de poder en la cotidianidad. Las investigaciones en este campo entrelazan teoría y metodología de ámbitos como la economía política, la comunicación, la sociología, la teoría social, la teoría literaria, la teoría de los medios de comunicación, el cine, la antropología cultural, la filosofía y el estudio de fenómenos culturales en las diversas sociedades.

3 "La teoría feminista, en cuanto teoría tiene que ver con el sentido original del vocablo teoría: hacer ver" (Amorós y de Miguel, 2005, p. 16).

4 Es la expresión más cercana al movimiento jesuánico cuyo talante contracultural y reivindicador de la igualdad de varones y mujeres ha sido objeto de estudio de la teóloga alemana Elisabeth Schüssler Fiorenza en su obra
Cristología feminista crítica, publicado por Editorial Trotta en el año 2000 (Vásquez Monzón, 2006).

Recomiendo el ensayo sobre las imágenes de la mujer en el arte medieval de Chiara Frugoni (2000), La mujer en las imágenes, la mujer imaginada. En Duby, G. y Perrot, M. (Dir.). Historia de las mujeres 2. La Edad Media (pp. 432-469). Madrid: Santillana Ediciones.

El preciosismo es un ejemplo de estos movimientos. Desde un simple dormitorio transformado en salón, las "preciosas" contribuyeron a la expansión de las letras a través de conversaciones sobre crítica literaria y lingüística. Estas mujeres, solteras en su mayoría, tuvieron gran influencia en la aparición de las primeras escritoras del siglo XIX (Perrot, 2011).

7 Sobre la participación de las mujeres en las insurrecciones parisinas sugiero revisar el estudio de Dominique Godineau (1993), Hijas de la libertad y ciudadanas revolucionarias. En Duby, G. y Perrot, M. (Dirs.). Historia de las mujeres. El siglo XIX. La ruptura política y los nuevos modelos sociales (pp. 23-39). Madrid: Taurus Ediciones.

J. P. Moebius publicó en 1900 la obra titulada La inferioridad mental de la mujer. 
9 En las teorías sobre la feminidad en el siglo XVIII, se afirmaba que la vida de la mujer se movía a impulsos de sus inclinaciones sentimentales, de esta cualidad esencial emanaban el coraje, el valor, la paciencia, la entrega (Moránt Deusa, 1997).

10 Nacida en Capadocia, Macrina fue educada en el seno de una familia con gran acervo teológico: su abuela llamada Macrina la mayor había estudiado teología con Gregorio el taumaturgo; su madre le enseñó la filosofía griega y la teología cristiana (Buss Mitchell, 1998, p. 127).

11 Resulta paradigmático el caso de la filósofa Hypatia de Alejandría (305-405), quien murió quemada a manos de un grupo de monjes por ser una filósofa y astrónoma pagana.

12 Para profundizar en el tema sugiero los textos de: Georgette Epiney-Burgard y Emile Zum Brunn, (1998). Mujeres trovadoras de Dios. Una tradición silenciada en la Europa Medieval. Barcelona: Ediciones Paidós Ibérica; Blanca Garí (Ed.). (2005). El espejo de las almas simples: Margarita Porete. Madrid: Ediciones Siruela; Verónica Martínez y Alejandra Reta. El lenguaje secreto de Hildegard von Bingen, vida y obra. (2003). México, D.F.: FCE/UNAM/ Editorial Espejo de viento.

13 Para un estudio más amplio sobre el tema de las utopías recomiendo el texto de Juan José Tamayo, (2012). Invitación a la utopía. Estudio histórico para tiempos de crisis. Madrid: Trotta.

14 El original está digitalizado en la Biblioteca digital mundial, recuperado de: http://www.wdl.org/es/ item/4391/\# q=El+libro+de+la+ciudad+de+las+damas \&view type $=$ list \&search_page $=1 \& q$ la $=e s$

Para un análisis más completo de esta obra sugiero consultar el texto de Soledad Barrios y Vanina Guazzaroni (2011), Christine de Pizan y la Ciudad de las Damas: la mujer como sujeto jurídico activo. La Aljaba, Vol. XV, pp. 175-186.

Lucrezia Marinella (1601). La nobilta et l'eccellenza delle donne, co' diffetti, et mancamenti de gli huomini. Venezia: Batista Ciotti Senese.

17 Michelle de Montaigne la consideró su "hija adoptiva”. Su obra incluye comentarios a la obra de Montaigne, ensayos morales y feministas (Otero Vidal, 1997, p. 85).

La obra de Sor Juana Inés de la Cruz ha sido considerada como la expresión novohispana de la querella de las mujeres (Ratto, 2002).

19 El texto en español fue editado por Daniel Cazés Menache (2007), Obras feministas de Fracois Poulain de la Barre (1647-1723) Tomo III. México: UNAM, Centro de Investigaciones Interdisciplinarias en Ciencias y Humanidades. 
20 En cuestión política, de Gouges era de tendencia moderada, partidaria de la monarquía constitucional. Fue condenada a la guillotina por la publicación de un texto titulado "Las tres urnas", en el que pedía un plebiscito entre gobierno republicano unitario, federación o monarquía. Incluso en la cárcel criticó duramente la dictadura de Robespierre (Puleo, 1993).

21 Filósofa y literata inglesa que dirigió la escuela de Newington Green (1783-1786), con el ya famoso círculo reformista creado en torno al pastor disidente Richard Price (1723-1791). El círculo que Wollstonecraft frecuentó en Newington Green pertenecía en su mayoría a la Iglesia Unitaria y cultivaba una tradición de "cristianismo racional" que insistía en el uso libre de la razón de la práctica religiosa (Burdiel, 2000, p. 29).

22 El original se titula Das Urbild der Menschheit. Ein Versuch, Dresden: in der Aruoldifchen Buchhandlung, 1811.

23 Roig cita también El Diario de la vida humana (Dresde, 1811) y las Lecciones de Derecho Natural (Gotinga, 1828).

24 Ver Vásquez Monzón (2014), Mujeres en público, el debate sobre la educación femenina entre 1871 y 1889. San Salvador: UCA Editores.

25 Para profundizar en este aspecto recomiendo el estudio de
Geneviéve Fraisse (1991), Musa de la razón. Madrid: Ediciones Cátedra. La autora examina las implicaciones de la diferencia sexual en la naciente democracia del período inmediatamente posterior a la Revolución francesa. Celia Amorós y Ana de Miguel (2005) agruparon las diferentes expresiones del feminismo en tres vertientes: feminismos de la diferencia, cuya reivindicación principal es la singularidad de las mujeres; feminismos de la igualdad, cuya pretensión es subvertir la lógica binaria de dominación de la sociedad patriarcal; y los llamados feminismos posmodernos y poscoloniales. Estos últimos, también llamados del tercer mundo, agrupan todas aquellas reivindicaciones asociadas a los derechos de los pueblos y la naturaleza; la incursión de las mujeres indígenas en la política pública; las posibilidades de liberación feminista desde las teologías cristianas disidentes; y las nuevas formas de masculinidad (Coba y Herrera, 2013).

27 Baring, A. y Cashford, J. (2005). El mito de la diosa. México, D. F.: FCE; Campbell, J. (2014). El héroe de las mil caras. Psicoanálisis del mito. México, D. F.: FCE; Campbell, J. (2014). Los mitos. Su impacto en el mundo actual. Barcelona: Kairós; Cassirer, E. (2011). Antropología filosófica. Introducción a una filosofía de la cultura. México, D. F.: FCE; Duch, L. (2004). Estaciones del 
laberinto. Ensayos de antropología. Barcelona: Herder; Gadamer, H. G. (1997).Mitoy razón. Madrid:Paidós; Pinkola Estés, C. (2005). Mujeres que corren con lobos. Barcelona: Zeta de Bolsillo; Zambrano, M. (2012). Hacia un saber sobre el alma. Madrid: Alianza Editorial; Zweig, C. y Wolf, S. (2008). Vivir con la sombra. Iluminando el lado oscuro del alma. Barcelona: Kairós.

28 Para profundizar en este tema recomiendo el ensayo de Jan Assmann (2014), Violencia y monoteísmo. Barcelona: Fragmenta Editorial.

29 El texto Diosas, publicado en 2013, recoge más de 20 conferencias del autor entre 1972 y 1986. 